Journal of Biotechnology and Strategic Health Research

Olgu Sunumu / Case Report

http://dergipark.org.tr/tr/pub/bshr

\title{
Maksillada Ektopik Kanin ile İlişkili Büyük Dentigeröz Kist: Olgu Sunumu
}

\section{Large Dentigerous Cyst Associated with Ectopic Canine of the Maxilla: A Case Report}

هidvan Güler, (1) Kamil Serkan Ağaçayak

Dicle Üniversitesi Diş Hekimliği Fakültesi, Ağız Diş ve Çene Cerrahisi AD, Diyarbakır

\begin{tabular}{|c|c|c|}
\hline \multicolumn{3}{|c|}{ ORCID ID: Ridvan Güler 0000-0003-4750-9798, Kamil Serkan Ağaçayak 0000-0002-6168-1802 } \\
\hline *Sorumlu Yazar / Corresponding Au & t. Rıdvan Güler, e-posta / e-mail: ridva & 6@gmail.comom \\
\hline Geliş Tarihi / Received : 16-04-2020 & Kabul Tarihi / Accepted: 28-04-2020 & Yayın Tarihi / Online Published: 30-04-2020 \\
\hline
\end{tabular}

$\ddot{\mathrm{Oz}}$

Dentigeröz kistler çenelerin sık gözlenen odontojenik kistleri arasında olup sıklıkla gömülü mandibular 3. molar dişler ile ilişkilidirler. Bu patolojiler daimi dişlerin kronlarını içine alan iyi huylu kitlelerdir. Genellikle asemptomatik olup dental radyografilerde tesadüfen tespit edilirler. Enfekte oldukları durumda ağrı semptomu oluşturabilirler. Erkeklerde, kadın hastalara oranla iki kat daha fazla görülür ve ortalama görülme yaşı 2. ve 3. dekatlardır. Kistlerin tedavisinde tercih edilecek yöntem; kistin boyutlarına, lokalizasyonuna ve anatomik yapılara uzaklığına bağlı olarak değişebilmektedir. Bu makalede 33 yaşında kadın hastada maksiller kanin dişten kaynaklanan büyük dentigeröz kist olgusu ve enükleasyon ile cerrahi tedavi süreci sunulmuştur. Dentigeröz kistler semptomsuz bir şekilde geniş kemik defektlerine yol açabilir. Bu yüzden tüm gömülü dişlerde radyografik inceleme yapılması oldukça önemlidir.

Anahtar Dentigeröz kist, enükleasyon, maksilla

Kelimeler

\begin{tabular}{ll}
\hline Abstract & \\
\hline & Dentigerous cysts are among the frequently encountered odontogenic cysts, and they are often associated with impacted mandibular third \\
molar teeth. These pathologies are benign masses which involve crowns of permanent teeth. They are often asymptomatic and detected during \\
routine dental radiographs. Though when they get infected, they may produce pain symptoms. They are twice as commonly encountered in \\
male patients compared to female patients, and the average age of onset is 20 s and 30s. The optimal method in treatment of cysts varies depen- \\
ding on the size of the cyst, its localization and its distance to anatomical structures. This article presents a case of large dentigerous cyst due to \\
maxillary canine tooth in a 33-year-old female patient, together with the surgical treatment process by way of enucleation.Dentigerous cysts can \\
cause wide bone defects without manifesting any symptoms. Therefore, radiographic examination is critical importance for all impacted teeth.
\end{tabular}

Keywords Dentigerous cyst, enucleation, maxilla 


\section{GİRIŞ}

Dentigeröz kistler, 1992 yılında Dünya Sağlık Örgütü (WHO) tarafından yapılan sınıflandırmaya göre odontojenik gelişimsel kist olarak kabul edilmiştir.ı Bu kistler, sıklıkla sürmemiş bir dişin kronu ile ilişkili olup radiküler kistlerden sonra çenelerin en yaygın görülen ikinci odontojenik kistidir.2 Dentigeröz kist sıklıkla mandibulada posterior bölgede 3. molar diş ile birlikte ortaya çıkarken, maksillada kanin ve 3. molar diş ile birlikte görülür. Odontojenik kistlerin ortalama \%24'ünü dentigeröz kistler oluşturmaktadır.4 Erkeklerde, kadınlara oranla iki kat daha fazla görülür ve ortalama 2 ve 3. dekatlarda daha sık görülmektedir.s

Dentigeröz kistler çeneler içerisinde gömülü dişin kronunun oluşmaya başlamasından sonra diş folikülü etrafında bir boşluk oluşması ve mine epitel artıklarının kistik değişime uğraması sonucu meydana gelmektedir.6 Bu kistler enfekte olmadıkça ve büyük hacimlere ulaşmadıkça asemptomatik seyrederler.6

Radyografta, sıklıkla gömülü bir dişin kronu ile ilişkili sklerotik sınırlara sahip uniloküler radyolüsent görüntü verirler.7 Fakat bazen multiloküler ve kenarları tarak şeklinde devamlılığı kaybolmuş radyografik görüntüde ortaya çıkarabilir.8 Histopatolojik olarak dentigeröz kist, fibröz bağ dokusu ile çevrili keratinize olmayan çok katlı skuamöz epitel ve odontojenik kalıntılardan oluşmaktadır. Bazen kronik mononükleer inflamatuvar hücre infiltrasyonuda izlenebilir.9

Kistlerin tedavisinde tercih edilecek yöntem; kistin boyutlarına, lokalizasyonuna ve anatomik yapılara uzaklığına bağlı olarak değişebilmektedir.10 Tedavide en sık kullanılan cerrahi yöntemler enükleasyon, marsüpyalizasyon ve kistin dekompresyonudur.10 Enükleasyon etkilenen dişin ve kist epitelinin tümüyle eksizyonu olup marsüpyalizasyona göre daha radikal bir tedavi seçeneğidir. Marsüpyalizasyon ise geniş boyuttaki kistlerin tedavisinde, düşük komplikasyon oranıyla etkili bir tedavi yöntemidir.10 Bu kistler tedavi edilmediği durumda, patolojik kemik kırıklarına ve çenede asimetriye yol açabilir. Ayrıca ameloblastoma, skuamöz hücreli karsinom ve mukoepidermoid karsinom gelişimine neden olabilmektedir.11

$\mathrm{Bu}$ vaka raporunda, 33 yaşında kadın hastanın sol maksillada bulunan kanin diş ile ilişkili büyük dentigeröz kistin enükleasyon ile tedavisi sunulmaktadır.

\section{OLGU}

33 yaşında kadın hasta, kliniğimize sol maksiller bölgede yaklaşık 2 haftadır devam eden ağrı ve şişlik şikâyeti ile başvurdu. Hastadan alınan anamnezde yakın zamanda travma öyküsünün olmadığı öğrenildi. Medikal hikâyesinde sistemik hastalık bulgusu olmayan hastanın ekstraoral muayenesinde, sol fossa kanina bölgede, hassas ve fluktuan özellikte şişlik olduğu izlendi. İntraoral muayenede, sol maksiller kanin dişinin henüz sürmediği gözlenmiş olup akut enfeksiyon belirtisi izlenmedi. (Resim 1) Hastanın panoramik radyografı incelendiğinde, sol maksiller kanin dişi içine alan uniloküler, sınırları belirgin radyolüsent alanlar izlenmiş olduğu ve kanin dişinin sol burun kanad1na doğru yer değiştirdiği görüldü. (Şekil 2) Sol maksillada lokalize lezyon, medialde burun lateral duvarı, inferiorda keser ve premolar-molar dişlerin apeksleri, superior ve posteriorda ise maksiler sinüs ile komşuluk yaptığı görüldü. (Resim 2)

Kitle sınırlarının komşu anatomik yapıları ile ilişkisinin detaylı incelenmesi amacıyla hastadan konik ışınlı bilgisayarlı tomografi (CBCT) alındı. Dental tomografik görüntülerde sol maksiller kanin dişin gömülü kaldığı, etrafında kistik lezyon geliştiği izlendi. Bununla birlikte kistik yapının komşu bukkal kemikte yer yer rezorpsiyona neden olduğu ve komşu diş apeklerinde migrasyona neden olduğu, maksiler sinüsü posteriora doğru ekspanse ettiği izlendi. Dental tomografik kesitlerde, kitlenin $4 * 4 * 1,5 \mathrm{~cm}$ boyutlarında olduğu ve nazal mukozada perforasyon olmadığ 1 izlenmiştir. (Resim3) Klinik ve radyolojik bulgulara bakılarak dentigeröz kist ön tanısı koyulan kitleye öncelikli 
olarak aspirasyon biyopsi işlemi yapıldı. Aspirasyon biyopsisi kitlenin kistik bir patoloji olduğunu doğruladı.

Hastadan bilgilendirilmiş onam alındıktan sonra lokal anestezi altında dentigeröz kist ön tanılı patolojik kitlenin enükleasyonu için ameliyata alındı. Öncelikle süt kanin dişin çekimi yapıldı. Ardından sulkuler ve vertikal insizyon yapılarak mukoperiostal flep kaldırıldı. Maksiller bukkal kemikte incelme ve perforasyonlar mevcut idi. Kist epiteli ve gömülü kanin dişe ulaşılarak tümüyle enükle edildi.(Resim 4-5) Kist boşluğunun serum fizyolojik ile irrigasyonu yapılıp bölgeye postoperatif enfeksiyonu önlemek amacıla \%0,2'lik Nitrofurazon emdirilmiş ekstrafor yerleştirildi. İşlem sonrası hastaya antibiyotik, analjezik ve ağız gargarası reçete edildi. Mukozaya sutüre edilen ekstrafor 3 gün sonra çıkarıldı. 7. gün süturları alınan hastada postoperatif olarak iyileşmede problem izlenmedi. Kitlenin histopatolojik değerlendirilmesinde nonkeratinize çok katlı yassı epitel ile döşeli subepitelyal alanda, lenfoplazmositer kronik inflamatuvar hücreler ve yer yer goblet hücreleri izlendiği rapor edildi. Kitleye histopatolojik inceleme sonucunda dentigeröz kist tanısı konuldu. (Resim 6) Hastanın 6 aylık iyileşme periyodunun ardından alınan panoramik radyografisinde kemik dokusunun remodelingi gerçekleşmiş olup herhangi bir nüks saptanmadı. (Resim 7)

\section{TARTIŞMA}

Odontojenik kistler maksillofasiyal bölgede sık görülen lezyonlardır. Etiyolojilerine göre enflamatuar ve gelişimsel olarak ikiye ayrılmaktadır. İnflamatuar kistler radiküler ve lateral periodontal kistler olarak, gelişimsel kistler ise primordial kist, dentijeröz kist, erüpsiyon kisti ve gingival kistler olarak sınıflandırılmaktadır.12 Dentigeröz kist en sık görülen ikinci odontojenik kisttir.13 Meningaud ve ark. yapmış oldukları bir çalışmada 695 odontojenik kist olgusu incelenmiş ve en sık teşhis edilen iki kistin radiküler kist (\%53.5) ve dentigeröz kist (\%22.3) olduğunu bildirmişlerdir.14 Literatürde görülme sıklığ $1 \% 9$ ile \%38 arasında olduğu rapor edilmiştir.15
Sıklıkla hayatın 2. ve 3. dekatlarında görülürken, erkeklerde kadınlara oranla iki kat daha sık görüldüğü rapor edilmiştir.5 Rapor ettiğimiz olguda hastanın 33 yaşında olması literatürü destekler niteliktedir. Dentigeröz kistlerin yaklaşık olarak \%70'i mandibulada, \%30'u ise maksillada görülmektedir.16 Rapor ettiğimiz bu olgu literatürün aksine maksillada ve kadın hastada görülmüştür.

Dentigeröz kistler sıklıkla mandibulada 3. molar diş ile maksillada ise kanin ve 3. molar diş ile birlikte görülür.s Fakat birçok çalışmanın aksine Motamedi ve ark. tedavi ettikleri 40 dentigeröz kist vakasını sundukları çalışmalarında gömülü kanin diş ile ilişkili dentigeröz kist oranının (\%45) 3. molar diş ile ilişkili kist oranından (\%30) daha fazla olduğunu rapor etmişlerdir. $17 \mathrm{Bu}$ olgu Motamedi ve arkadaşlarının 17 yapmış olduğu çalışmayı destekler niteliktedir.

Dentigeröz kistler sıklıkla asemptomatik olarak seyreder. Fakat büyük boyutlara ulaştıklarında dişlerde migrasyon, çevre dokularda ekspansiyon, rezorpsiyon, yüzde asimetriye ve maloklüzyona neden olabilirler.13 Bunun yanı sıra dentigeröz kistin neden olduğu inferior alveoler sinir parestezisi de bildirilmiştir.18 Rapor edilen bu olgudaki dentigeröz kist, hastada herhangi bir semptom oluşturmadan çene kemiğinde ileri yaşa kadar yayılım göstererek ciddi boyutlara ulaşmıştır.

Gömülü dişilerdeki 3-4 mm'lik folikül genişliği normal kabul edilmektedir. Bu genişlik 5 mm'den daha fazla olduğunda dentigeröz kist şüphesi asla göz ardı edilmemelidir.8 Radyografik olarak dentigeröz kistler çoğunlukla gömülü dişin kronu ile ilişkili, uniloküler sklerotik marjinlere sahip iyi sınırlı radyolüsent bir lezyon olarak görüntü verir.7 Bu olguda sol maksillada kanin dişi içine alan sınırları belirgin, uniloküler radyolüsent alanlar izlenmiş olup literatürü destekler niteliktedir.

Dentigeröz kistin ayırıcı tanısında; primordial kist, radiküler kist, travmatik kemik kisti, anevrizmal kemik kis- 
ti, ameloblastoma, ameloblastik fibroma, adenomatoid odontojenik tümör, odontojenik miksoma ve keratositik odontojenik tümör düşünülmelidir.19

Dentigeröz kistin başlıca tedavisi seçenekleri enükleasyon ve marsüpyalizasyondur.2 Kist olgularında cerrahi yönteme karar verirken dikkatlice değerlendirilmesi gereken noktalar; hastanın yaşı, kistin hacmi ve oluştuğu bölge, dentisyon varlığı, vital dokularla ilişkisi, estetik kaygılar, cerrahi sonrasında nöral yapılara zarar verme riskidir. 17 Kist ile ilişkili olan 3. molar diş veya supernumerer diş olduğunda kistin tümüyle enükleasyonu ilk seçenek olmalıdır. Bunun yanı sıra kist ile ilişkili dişin korunması isteniyorsa veya çene fraktür riski oluşabilecek büyük hacimli kistlerde başlangıçta marsüpyalizasyon yapılması, sonrasında enükleasyon ile birlikte dişin çekimi savunulmaktadır.7 Enükleasyon etkilenen dişin ve kist epitelinin tümüyle eksizyonu olup marsüpyalizasyona göre daha kısa süreli bir tedavi seçeneğidir. Marsüpyalizasyon enükleasyona oranla daha konservatif bir tedavi yaklaşımıdır. Bir diğer avantajı ise anatomik yapıların ve diş germlerin korunmasıdır. Marsüpyalizasyonun en büyük dezavantajı uzun süreli bir tedavi olmasıdır.7 Sunulan olguda, kistin izole olması ve anatomik yapılardan uzak olmasından dolayı enükleasyon tedavi seçeneği tercih edilmiştir.

Sonuç olarak, dentigeröz kistler sıklıkla asemptomatik olarak büyüdüklerinden, semptomsuz geniş kemik defeklerine neden olabilirler. Bundan dolayı dental muayene s1rasında sürmemiş diş bölgelerinden radyografik inceleme yapılması oldukça önemlidir.
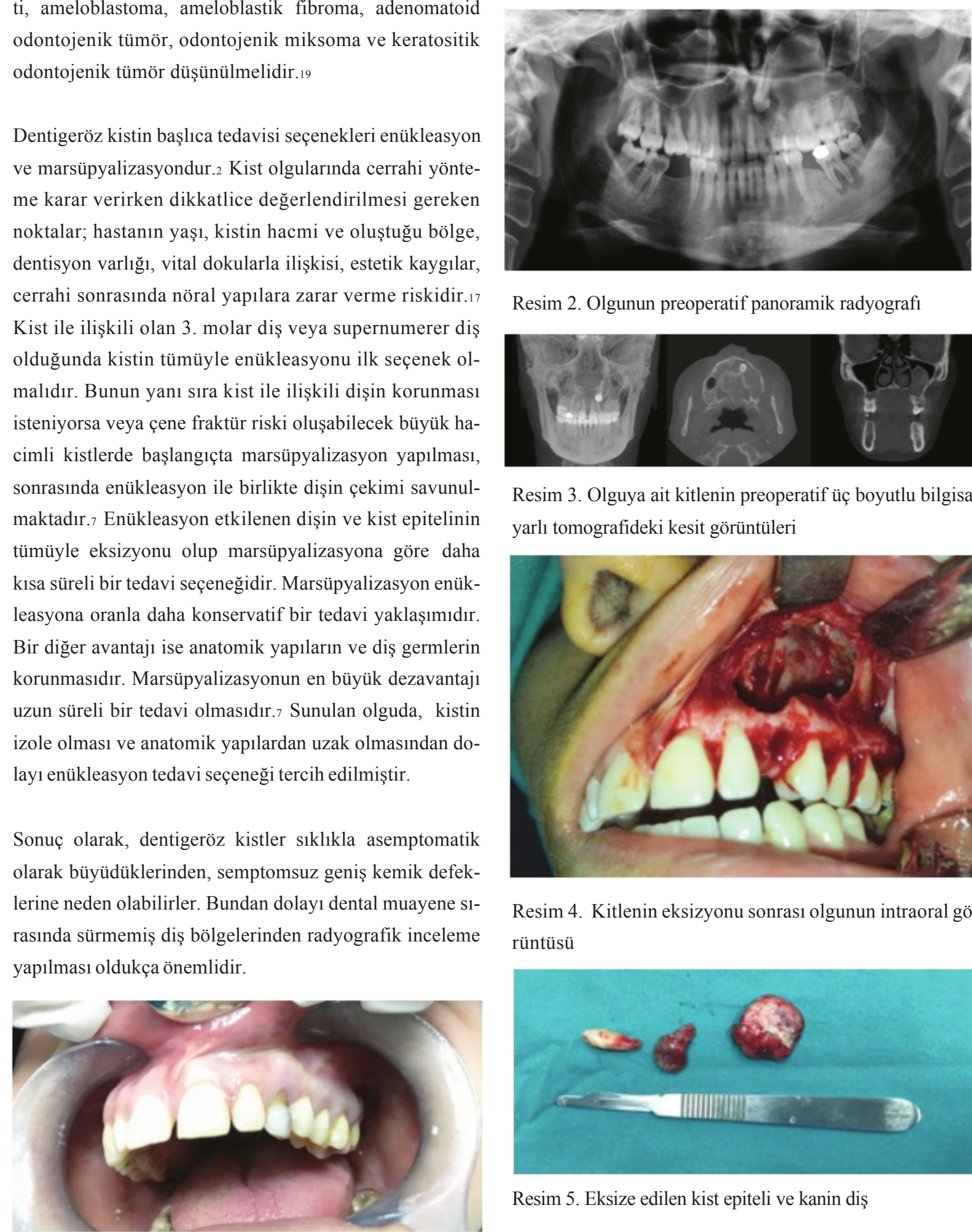

Resim 2. Olgunun preoperatif panoramik radyografi

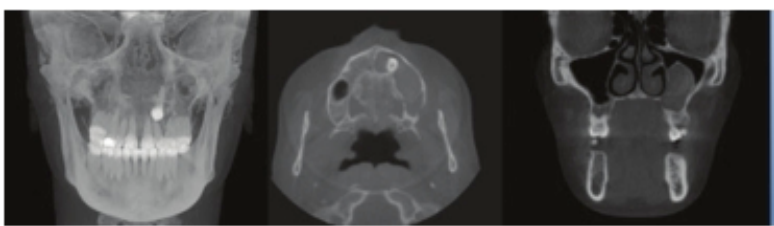

Resim 3. Olguya ait kitlenin preoperatif üç boyutlu bilgisayarlı tomografideki kesit görüntüleri

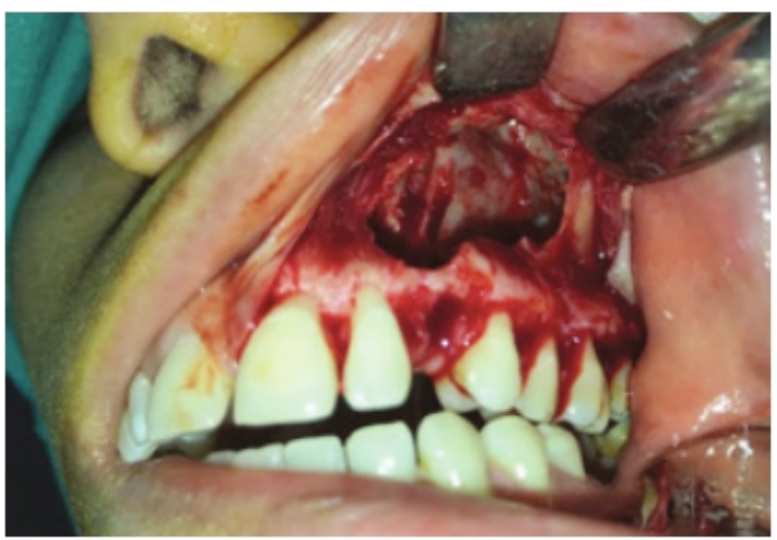

Resim 4. Kitlenin eksizyonu sonrası olgunun intraoral görüntüsü

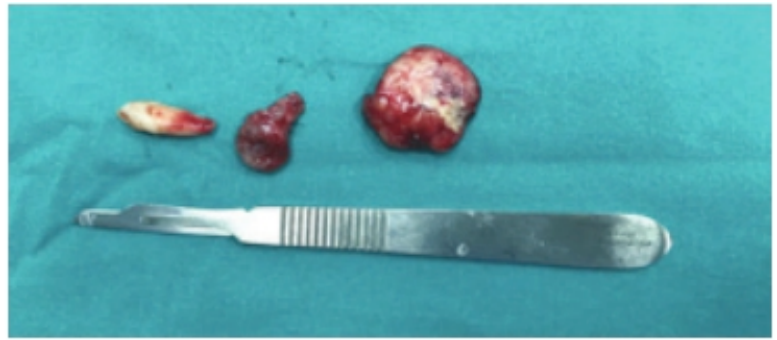

Resim 5. Eksize edilen kist epiteli ve kanin diş

Resim 1. Olgunun preoperatif intraoral görüntüsü 


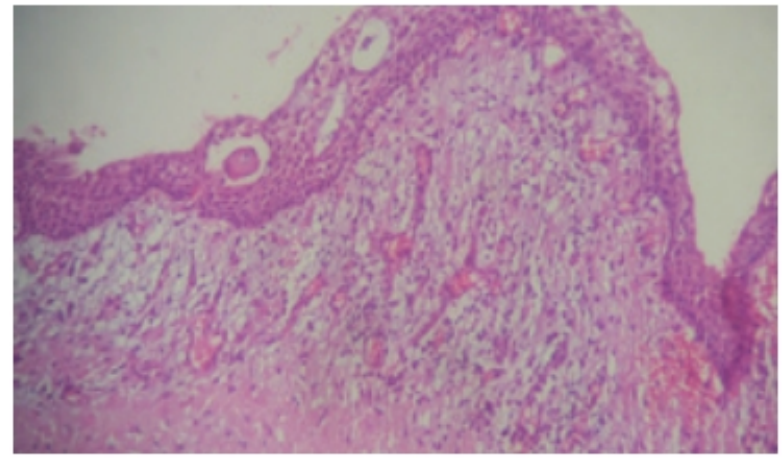

Resim 6. Histopatolojik görünüm (HEX100)

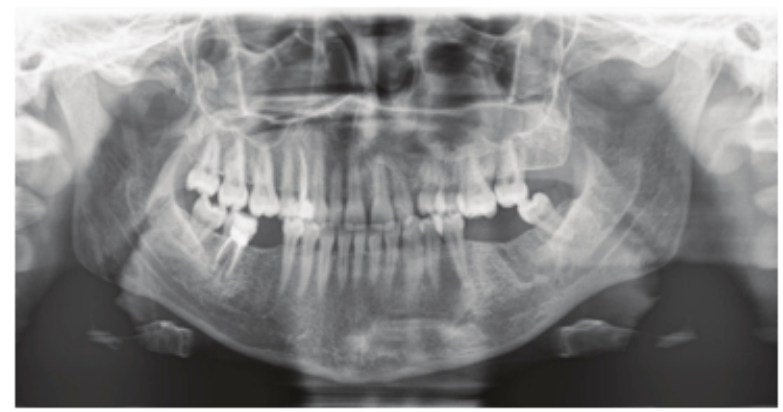

Resim 7. Hastanın postoperatif panoramik radyografi (6.ay)

Bu olgu, 24-28 Nisan 2019 tarihinde 13th AÇBİD International Oral \& Maxillofacial Surgery Society Congress'de poster bildirisi olarak sunulmuştur.

\section{Bilgilendirme}

Çalışmayı maddi olarak destekleyen kişi/kuruluş yoktur. Yazarların herhangi bir çıkar dayalı ilişkisi bulunmamaktadir. 


\section{Kaynaklar}

1. Korkmaz YT, Aral İL. Mandibulada Bilateral Dentigeröz Kist: Vaka Raporu. Cumhuriyet Üniversitesi Diş Hekimliği Fakültesi Dergisi. 2009; Cilt: 12 Sayı: 2.

2. Smith JL, Kellman RM. Dentigerous cysts presenting as head and neck infections. Otolaryngol Head Neck Surg. 2005; 133: 715-717. doi:10.1016/j.otohns.2005.07.014

3. Özkan A, Okçu KM, Sençimen M, ve ark. Nonsendromik bilateral mandibular dentigeröz kist: olgu sunumu. Gülhane Tip Derg. 2011; 53: 52-55.

4. McCrea S. Adjacent dentigerous cysts with the ectopic displacement of a third mandibular molar and supernumerary (forth) molar: a rare occurrence. Oral Surg Oral Med Oral Pathol Oral Radiol Endod. 2009; 107 (6): e15-20. doi:10.1016/j.tripleo.2009.02.002.

5. Delbem AC, Cunha RF, Afonso RL, et al. Dentigerous cysts in primary dentition:Report of 2 cases. Pediatr Dent. 2006; 28(3): 269272.

6. Usalan G, Erten H, Akpınar D. Dentigeröz kist ( üç olgu ). SÜ Diș. Hek. Fak. Derg. 2008; 17: $126-130$.

7. Tayşi M, Ozden C, Cankaya AB, et al. Conservatıve Approach To A Large Dentıgerous Cyst In An 11-Year-Old Patıent. J Istanbul Univ Fac Dent. 2016; 50(3): 51-56.

8. Cury SE, Cury MD, Cury SE, et al. Bilateral dentigerous cyst in a nonsyndromic patient case report and literature review. J Dent Child (Chic). 2009; 76 (1): 92-6.

9. Kirtaniya BC, Sachdev V, Singla A, et al. Marsupialization: A conservative approach for treating dentigerous cyst in children in the mixed dentition. J Indian Soc Pedod Prev Dent. 2010; 28(3): 203-208. doi:10.4103/0970-4388.73795.

10. Yaqoob A, Wani TM, Ashraf J, et al. Conservative surgical management of adentigerous cyst associated with an impacted mandibular canine. Dentistry and Medical Research. 2014; Vol 2 Issue 2. doi:10.4103/2348-1471.143333.
11. Chakraborty A, Sarkar S, Dutta BB. Localised disturbances associated with primary teeth eruption. J Indian Soc Pedod Prev Dent. 1994; 12(1): 25-28. PMID: 9522742.

12. Öz I, Erkan AN, Yıldırım Ç. Maksiller Sinüsü Destrükte Eden Büyük Dentijeröz Kist: Olgu Sunumu. Acıbadem Üniversitesi Sağlık Bilimleri Dergisi. 2013; Cilt: 4 Sayı: 2.

13. Contar CMM, Thomé CA, Pompermayer A, et al. Marsupialization of Dentigerous Cyst: Report of a Case. J. Maxillofac. Oral Surg. 2015; 14(Suppl 1):S4-S6 doi: 10.1007/s12663011-0172-6. doi:10.1007/s12663-011-0172-6.

14. Meningaud JP, Oprean N, Pitak-Arnnop P, et al. Odontogenic cysts: a clinical study of 695 cases. J Oral Sci. 2006; 48: 59-62. doi:10.2334/josnusd.48.59.

15. Zhang LL, Yang R, Zhang L, et al. Dentigerous cyst: a retrospective clinicopathological analysis of 2082 dentigerous cysts in Biritish Bolumbia, Canada. Int J Oral maxillofac Surg. 2010; 39(9): 878-82. doi:10.1016/j.ijom.2010.04.048.

16. Srinivasa Prasad T, Sujatha G, Niazi TM, et al. Dentigerous cyst associated with an ectopic third molar in the maxillary sinus: a rare entity. Indian journal of dental research : official publication of Indian Society for Dental Research. 2007; 18.141-3. doi:10.4103/09709290.33793 .

17. Motamedi MH, Talesh KT. Management of extensive dentigerous cysts. Br Dent J. 2005; 26;198 (4): 203-6. doi:10.1038/sj.bdj.4812082.

18. Sumer M, Bas B, Yildiz L. Inferior alveolar nerve paresthesia caused by dentigerous cyst associated with three teeth. Med Oral Patol Oral Cir Bucal. 2007; 12:E388-E390.

19. Dinkar AD, Dawasaz AA, Shenoy S. Dentigerous cyst associated with multiple mesiodens: a case report. J Indian Soc Pedod Prev Dent. 2007; 128(2): 201-205. doi:10.4103/09704388.31994 